\title{
Shrinkages and warpage in the processability of wood-filled polypropylene composite thin-walled parts formed by injection molding
}

\begin{abstract}
Reducing volumetric shrinkages and warpage during the injection molding process is a challenging problem in the production of molded thin-walled parts. In this study, the injection molding of shallow, thin-walled parts (thickness $0.7 \mathrm{~mm}$ ), composed of lignocellulosic polymer composites (polypropylene (PP) $+50 \mathrm{wt} \%$ wood), was simulated. The volumetric shrinkages and warpage in the thin-walled parts were evaluated under different process conditions, with varying post-filling parameters, such as mold temperature, cooling time, packing pressure and packing time. The analysis showed that the cooling time and packing time had less of an effect on the shrinkage and warpage; nevertheless the optimal levels for both parameters are required in the molding process for the thin-walled part to achieve the best results. The volumetric shrinkage was lower near the gate than at the end-of-fill location along the flow path. The results also showed that the volumetric shrinkage correlates with the warpage measured on the molded part. The optimum parameters ranges is $40-45^{\circ} \mathrm{C}$ for the mold temperature; 20-30 s for cooling time; 0.85 from injection pressure (Pinject) for packing pressure; and 15-20 s for the packing time to achieve the best results with the least amount of volumetric shrinkage and warpage.
\end{abstract}

Keyword: Lignocellulosic composite; Thin-walled parts; Injection molding; Volumetric shrinkage; Warpage 